\title{
Improving Efficiency of Hybrid Electric Vehicle Using Matrix Converters
}

\author{
Branislav Dobrucky, Slavomir Kascak, Michal Prazenica, Miriam Jarabicova \\ Department of Mechatronics and Electronics, Faculty of Electrical Engineering and Information \\ Technologies, University of Zilina, \\ Univerzitná St. 1, SK-01026 Zilina, Slovakia \\ branislav.dobrucky@fel.uniza.sk
}

\begin{abstract}
The paper deals with a novel enhanced connection of AC/AC powertrain for HEV hybrid vehicles. The substantial contribution of such a connection is the absence of 4QC auxiliary converter needed for autonomous and hybrid operational modes and its compensation by power-lesser $0 \times 5$ matrix converter. The main advantages of a simplified connection are beside smaller auxiliary converter sizing and possible better efficiency of the HEV powertrain. So, powertrain operation in autonomous traction accu-battery modes uses direct $0 \times 5$ configuration of traction $3 \times 5 \mathrm{MxC}$ matrix converter and in hybrid modes of ICE engine and accubattery, besides traction $3 \times 5 \mathrm{MxC}$ matrix converter, uses the auxiliary $0 \times 5$ matrix converter. Modeling and simulation using Matlab-Simulink environment of traction powertrain configuration in autonomous modes are presented in the paper, as well as all simulation experiment results.
\end{abstract}

Index Terms-AC/AC powertrain; $3 \times 5$ matrix converter; $0 \times 5$ matrix converter; Five-phase induction motor.

\section{INTRODUCTION}

HEV vehicles have an important role in the automotive industry as well as in the national economy and in transport, and traffic services. From the point of view of electrical powertrain, there are considered possible types of the powertrain [1]-[4]:

1. Pure DC/DC powertrain based on DC generator (dynamo) and DC traction motor(s);

2. Mixed AC/DC one based on AC generator, AC/DC converter, and DC traction motor(s);

3. Mixed AC/DC/AC powertrain based on AC generator, AC/DC front converter, DC interlink, DC/AC end converter (VSI-inverter), and AC traction motor(s);

4. Pure AC/AC powertrain with $\mathrm{AC}$ generator, direct $\mathrm{AC} / \mathrm{AC}$ converter without $\mathrm{DC}$ interlink, and $\mathrm{AC}$ traction motor(s).

Although the personal HEV with DC/DC powertrain is not in use nowadays, some high-power dumpers (e.g., BelAZ, Russian Federation) are [2].

Mostly series HEV powertrains use front-end converter system with a DC-voltage interlink. Configuration with motor-wheels allows flexibility of the car; removes the

Manuscript received 12 November, 2018; accepted 18 April, 2019

This research was funded by APVV-15-0571: Research of the optimum energy flow control in the electric vehicle system, ITMS project No. 26210120021 co-funded from EU sources and European Regional Development Fund, and KEGA project No. 027ŽU-4/2018. central drive motor and associated transmission parts of the propulsion system of the vehicle. The main advantage of the electric motor in the wheel is adjustable traction and individual braking torque with high precision without ingestion gearbox, drive shaft, differential gear, and other complex and heavy parts of the power transmission [3]. One of such a traction system is shown in Fig. 1.

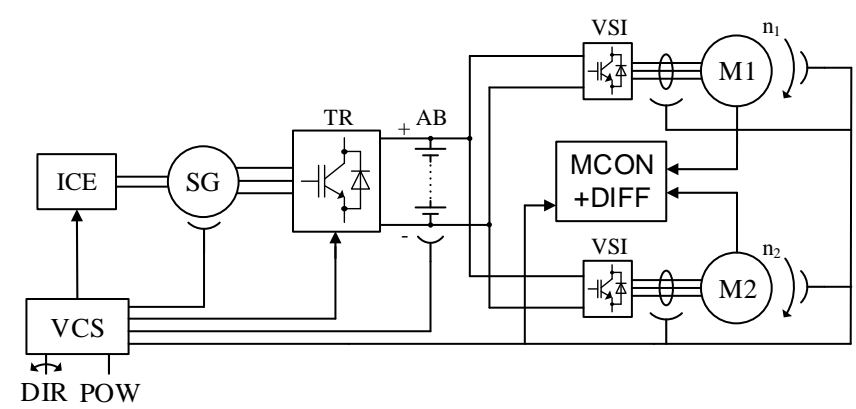

Fig. 1. Classical series HEV with two VSI converters, two motor wheels, and electronic differential: ICE - internal combustion engine, SG synchronous generator, TR - traction rectifier, $\mathrm{AB}$ - traction accu-battery, VSI - voltage source inverter, TM1,2 - traction motors, VCS - vehicle control system, and MCON - traction motors control.

\section{A. Potential Possibilities of Improving the Efficiency of AC/AC powertrain}

There are following potential possibilities for direct $\mathrm{AC} / \mathrm{AC}$ powertrain efficiency improving with a comparison to classical AC/DC/AC powertrain (see Fig. 1, [5], [6]):

1. to release the traction rectifier TR and substitution of $\mathrm{AC} / \mathrm{DC} / \mathrm{AC}$ powertrain by direct $\mathrm{AC} / \mathrm{AC}$ converter (matrix- or cyclo-converter type),

2. to change the classical inverse connected two IGBT switches by two antiparallel-connected reverse blocking RB_IGBT (or by two antiparallel-connected SCR thyristors),

3. to substitute classical 3-phase traction motors M1 and M2 by 5 -phase motors,

4. to use independent control of two traction motors fed by single $\mathrm{AC} / \mathrm{AC}$ converter,

5. to use software reconfiguration of direct $\mathrm{AC} / \mathrm{AC}$ converter for all operational modes of AC/AC powertrain.

\section{DIRECT AC/AC POWERTRAIN WITH EFFICIENCY CONTRIBUTION}

Structural scheme of $\mathrm{HEV}$ with $\mathrm{AC} / \mathrm{AC}$ powertrain is shown in Fig. 2. As it is shown [4], a good compromise 
among the different number of phases traction generator and traction motor is a three-phase generator and a five-phase motor, i.e., [3×5] direct converter. Such a configuration of the AC/AC powertrain makes it possible both pure electric operating modes and/or pure engine mode, as well as hybrid mode: the vehicle is propelled by ICE engine and accubattery energy in parallel operation [1].

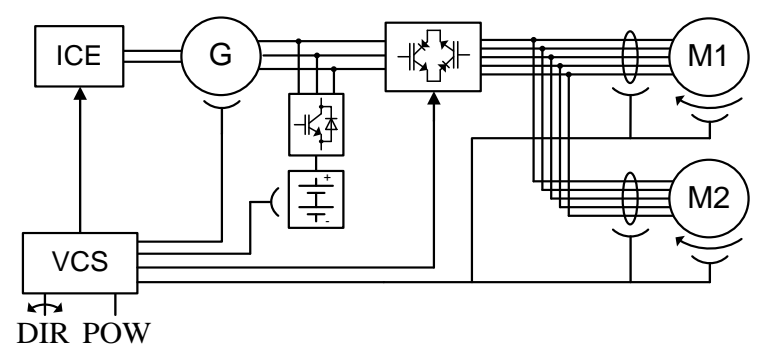

Fig. 2. Direct AC/AC series $\mathrm{HEV}$ with one $\mathrm{MxC}$ converter, one auxiliary 4QC battery converter, and two traction motors with independent control.

\section{A. Comparison of 3-Phase VSI Powertrain and 3-Phase Matrix Powertrains}

It is shown in the paper [7], [8] that when comparing matrix converter $(\mathrm{MxC})$ with VSI converter with an active front-end for induction motor drive, the matrix converter's semiconductor losses are smaller at full load operation for the same silicon area in both converters (11-22\% depending on switching frequency). A one-third reduction of the device current rating of the $\mathrm{MxC}$ is possible, resulting in comparable thermal device stress. Therefore, if total power losses of the electrical part of powertrain (converter and motor) are, let's say, $20 \%$ of the transmission power, then under the converter losses are $40 \%$ from that value. That means that the efficiency of the powertrain electrical part could be higher by $8-12 \%$. Regarding a number of phases, if the number of phases of the motor is three (no more), then there is not possible to connect both traction motors to one common direct traction converter [9], [10].

\section{B. Comparison of Three-Phase and Five-Phase Matrix Converters}

It is clear that the voltage is periodic and follows the desired amplitude and frequency. From [5], [11], [12], the following remarks can be deduced.

1. The five-phase application has the following advantages in comparison of the three-phases application:

- The speed curve response time dynamics is faster;

- The torque curve has fewer ripples rate;

- The value of the output voltage of converter is higher;

- Furthermore, the amplitude of the output current in five-phase is reduced compared to the three-phase (from 4.5 A to $3.5 \mathrm{~A}$ ), which can prevent deterioration of the windings and use smaller gauge switches (reduce the cost of purchase and maintenance).

2. Both applications have nearly the same properties regarding to input voltage and output current waveforms (almost a sine waveform), and regarding to disturbance, which is applied to both machines, the curves of speed have the same behaviors of load compensations (the decrease and increase of the speed due to the variation of the load are quickly corrected by PI controllers).

From the point of view of the powertrain efficiency, a simulation analysis of 3-phase and 5-phase VSI inverter is done, which can be used for indirect control operated matrix converter [11]. Modeling and simulation are described in Section III.

\section{Comparison of Direct AC/AC Powertrain with 4QC Battery Converter and [0×5] MxC Battery Converter}

One of the disadvantages of direct AC/AC powertrain with 4QC battery converter (Fig. 2) is that in autonomous traction mode, when powered $\mathrm{HEV}$, by battery total traction power flows through two converters. Therefore, we suppose new direct $\mathrm{AC} / \mathrm{AC}$ powertrain with $[0 \times 5] \mathrm{MxC}$ battery converter (see Fig. 3).

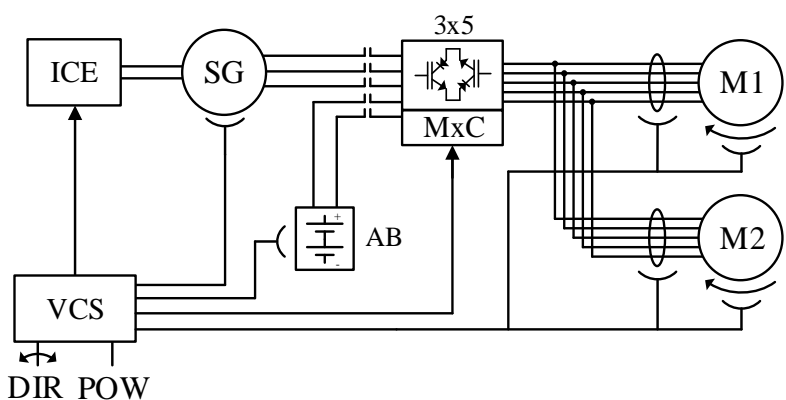

Fig. 3. Direct AC/AC series $\mathrm{HEV}$ with one $\mathrm{MxC}$ converter and one auxiliary [0x5] MxC battery converter.

Using this connection shown in Fig. 3, in autonomous traction mode, when powered $\mathrm{HEV}$, by battery total traction power flows just through one $[0 \times 5] \mathrm{MxC}$ converter, which can be easily created from [3×5] MxC [11]. Therefore, it clear that the efficiency of such a direct $\mathrm{AC} / \mathrm{AC}$ powertrain will be higher. Modeling and simulation are described in Section III.

\section{Comparison of IGBT and RB_IGBT}

In case IGBT switches have free-wheel diodes (reverse blocking RB_IGBT), the antiparallel connection of these two RB_IGBT can be used as a bidirectional switch in matrix converter connections. Such switches with an integrated diode in the collector of IGBT are developed by such electric companies as IXYS and FUJI.

From the point of view of the powertrain efficiency, reverse blocking transistors feature by higher efficiency and lower power losses, respectively. Following Fig. 4, it shows a comparison of classical and reverse blocking IGBTs regarding all kind of losses: on-state $P_{o n}$, saturation $P_{\text {sat }}$, switching $P_{o f f}$, and reverse recovery $P_{r r}$ ones. Values of the power losses depend on the switching frequency used in the tested circuit. Figure 4 is redrawn from [13]. Rising of the frequency from 2 to $20 \mathrm{kHz}$ causes the rise of the losses by $10 \%$.

From the Fig. 4, it is clear that total losses of the reverse blocking IGBTs are lower than classical IGBTs losses. Calculation and simulation of the losses are described in [14].

\section{E. Comparison of Three-Phase and Five-Phase IM Tractive Motors}

The five-phase machines offer some inherent advantages over their three-phase counterpart as mentioned above. Major advantages of using a five-phase machine instead of 
the three-phase ones consist in their higher torque density, greater efficiency, and fault tolerance. Other advantage includes reduced electromagnetic torque pulsation and reduction in the required rating per inverter leg. Noise characteristics of the five-phase drives are better when compared with the three-phase ones. [10], [11], [15].

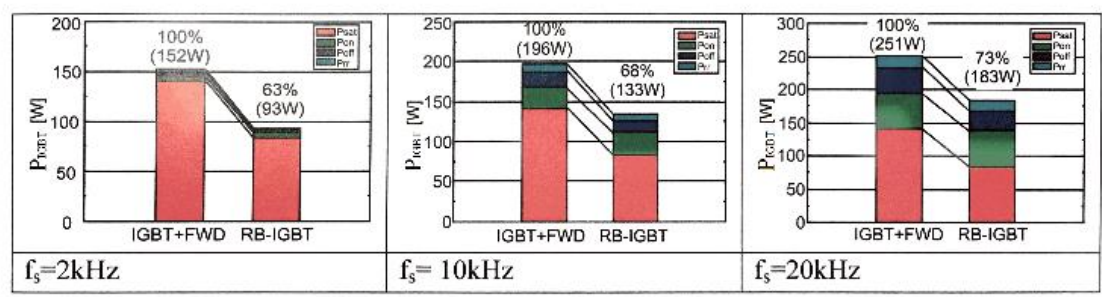

(a)

(b)

(c)

Fig. 4. The comparison of IGBTs with freewheel diodes and IGBTs with blocking diodes $\left(\mathrm{RB} \_\right.$IGBT): a) $\left.\left.-f_{s}=2 \mathrm{kHz}, \mathrm{b}\right)-f_{s}=10 \mathrm{kHz}, \mathrm{c}\right)-$

$f_{s}=20 \mathrm{kHz}$.

Higher phase number should yield smoother torque due to the simultaneous increase of the frequency of the torque pulsation and reduction of the torque ripple magnitude. Higher torque density in the five-phase machine is possible, although apart from the fundamental spatial field harmonics. The space field harmonics can be used to contribute to the total torque production. In a multi-phase machine with five or more phases, there are additional degrees of freedom, which can be used to enhance the torque production through the injection of higher-order current harmonics. In a fivephase induction machine, a third current harmonic injection can be used to enhance the overall torque production [10], [11], [15]. The studies on multi-phase drive system, carried out so far, are for the high-performance variable speed applications. The five-phase drive is seen as a serious contender for niche applications, such as ship propulsion, traction, lifts electric vehicles, and in safety-critical applications requiring high degree of redundancy. However, general purpose drive applications using multi-phase machines have not yet been investigated in detail.

\section{F. Comparison of Independent Control of Two Traction} Motors Fed by Single AC/AC Converter with Motors Fed by Two AC/AC Converters from the View of Efficiency

Using independent control of two traction motors fed by one single direct AC/AC converter instead of two ones (see Fig. 2), the power losses of the single converter are slightly lesser and the efficiency of the powertrain is higher, but it is not the essential increasing. However, as the authors say in [10], that although parallel multi-phase multi-motor drives and series connected multi-phase multi-motor drive systems are feasible and in principle offer good quality of dynamic performance as well, the users do not hold a real prospect for industrial applications so far.

\section{G. Software Reconfiguration of Direct AC/AC Converter for All Operational Modes of AC/AC Powertrain}

Unlike previous powertrain connection with VSI converter and DC link, the AC/AC powertrain with [3×5] matrix converter makes it possible to reconfigure basic

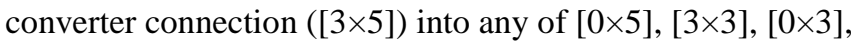
$[\times 0]$ ones. So, we can easily create $[3 \times 5]$ matrix connection for direct supplying of the powertrain from accu-battery through $[0 \times 5] \mathrm{MxC}$ to traction motors (Fig. 5(a) and Fig. $5(b))$ as mentioned above.

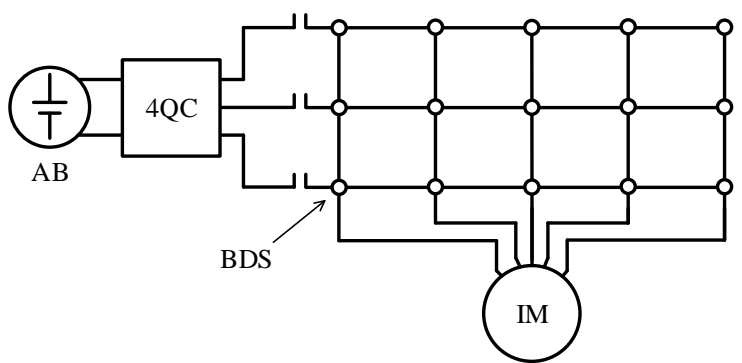

(a)

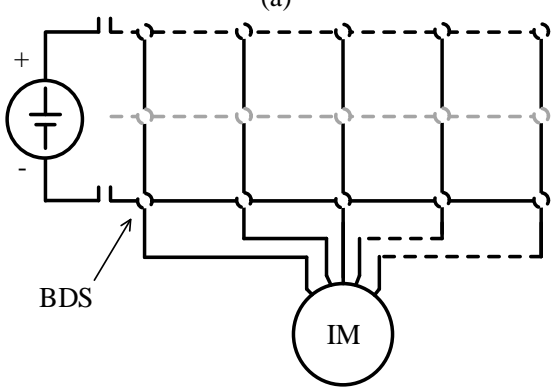

(b)

Fig. 5. Autonomous accu-battery mode with [3x5] MxC+4QC (a), and [0x5] MxC connection (b) - BDS-bidirectional switches.

\section{MODELING AND SimUlation}

A. Comparison of Direct AC/AC Powertrain with $4 Q C$ Battery Converter and [0×5] MxC Battery Converter of HEV Vehicle

The corresponding schemes of [3×3] and [3×5] $\mathrm{MxC}$ converters are presented in Fig. 6(a) and Fig. 6(b).

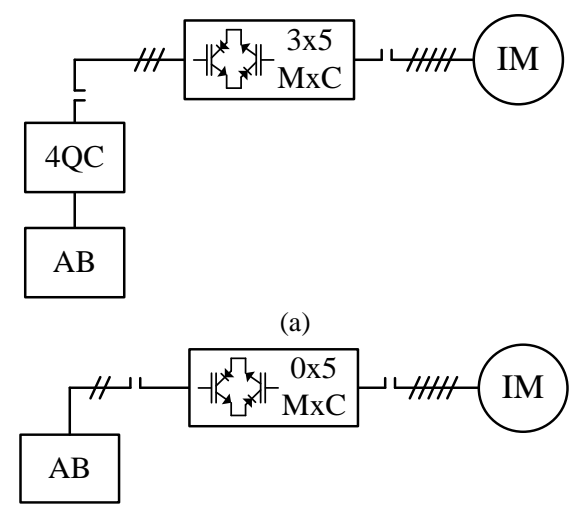

(b)

Fig. 6. Autonomous accu-battery mode through [3x5] and [0x5] MxC connection. 
In the case of $4 \mathrm{QC}+[3 \times 5] \mathrm{MxC}$ connection, the equivalent fictitious DC interlink voltage function $v_{\text {equ }}(t)$ can be calculated as difference of two potentials $V^{+}$and $V^{-}$ $([8],[11])$

$$
V_{D C}=V_{e q u}(t)=V^{+}(t)-V^{-}(t) .
$$

The difference of $V^{+}(t)$ and $V^{-}(t)$ potentials depend on the maximal and minimal values of input phase voltages $v_{R}(t), v_{S}(t)$, and $v_{T}(t)$ :

$$
\left(\begin{array}{c}
V^{+}(t) \\
V^{-}(t)
\end{array}\right)=\left(\begin{array}{lll}
R^{+} & S^{+} & T^{+} \\
R^{-} & S^{-} & T^{-}
\end{array}\right)\left(\begin{array}{c}
v_{R}(t) \\
v_{S}(t) \\
v_{T}(t)
\end{array}\right),
$$

where $R^{+} \ldots T^{-}$are logical variables for the maximal and minimal input phase voltages. The phase voltages can be calculated as in [5], [11]:

$$
\left[\begin{array}{l}
u_{a}(t) \\
u_{b}(t) \\
u_{c}(t) \\
u_{d}(t) \\
u_{e}(t)
\end{array} \mid=\left[\begin{array}{ll}
u_{m 1}(t) & 1-u_{m 1}(t) \\
u_{m 2}(t) & 1-u_{m 2}(t) \\
u_{m 3}(t) & 1-u_{m 3}(t) \\
u_{m 4}(t) & 1-u_{m 4}(t) \\
u_{m 5}(t) & 1-u_{m 5}(t)
\end{array} \mid\left[U^{+}(t)-U^{-}(t)\right],\right.\right.
$$

and stator voltages in $\alpha \beta$ coordinates as

$$
\begin{aligned}
& u_{s}=\frac{2}{5}\left(u_{a}+u_{b} e^{j \frac{2 \pi}{5}}+u_{c} e^{j \frac{4 \pi}{5}}+u_{d} e^{j \frac{6 \pi}{5}}+u_{b} e^{j \frac{8 \pi}{5}}\right)= \\
& =u_{\alpha}+j u_{\beta} .
\end{aligned}
$$

Then, using the math model of $7.5 \mathrm{~kW}$ IM traction motor, we can calculate corresponding phase voltages and currents:

$$
\begin{aligned}
\frac{d}{d t}\left(\begin{array}{c}
i_{s} \\
i_{r} \\
\omega_{m}
\end{array}\right) & =A\left(\begin{array}{c}
i_{s} \\
i_{r} \\
\omega_{m}
\end{array}\right)+B\left(\begin{array}{c}
u_{s} \\
u_{r} \\
0
\end{array}\right), \\
\frac{d}{d t} \omega_{m} & =\frac{T_{\text {elmg }}-T_{\text {load }}}{J_{m}} .
\end{aligned}
$$

Carried-out simulation results for $4 \mathrm{QC}+[3 \times 5] \mathrm{MxC}$ connection are shown in Fig. 7(a), Fig. 7(b) and [0x5] MxC in Fig. 8(a) and Fig. 8(b).

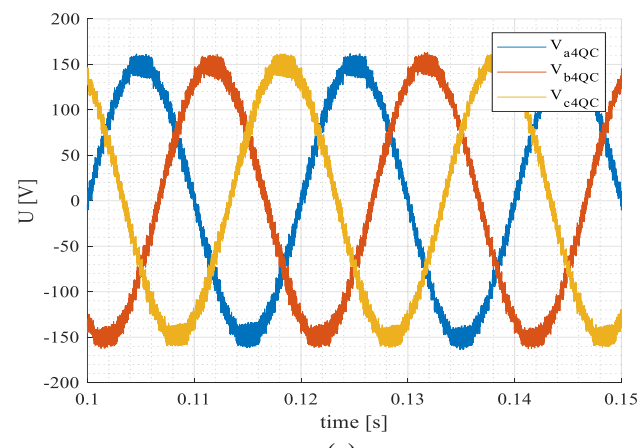

(a)

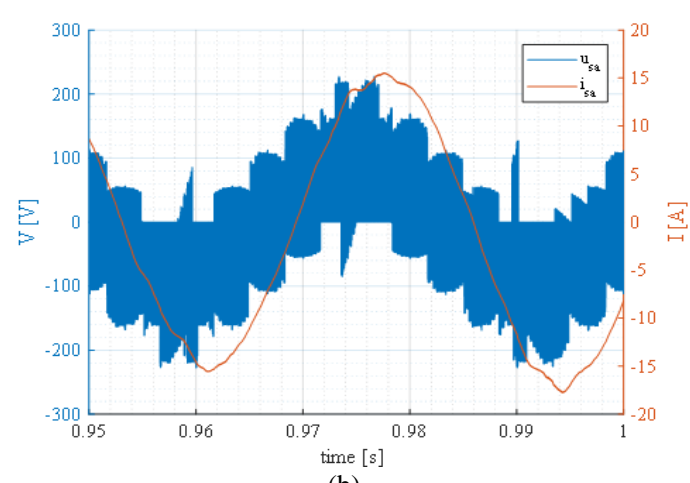

(b)

Fig. 7. Autonomous accu-battery mode through both 4QC+[3×5] MxC (a), (b).

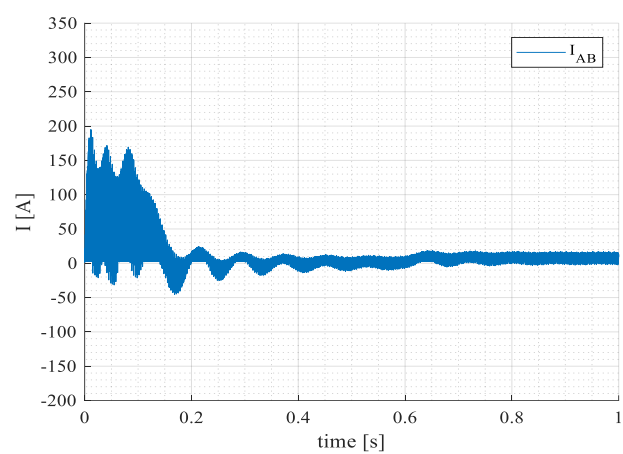

(a)

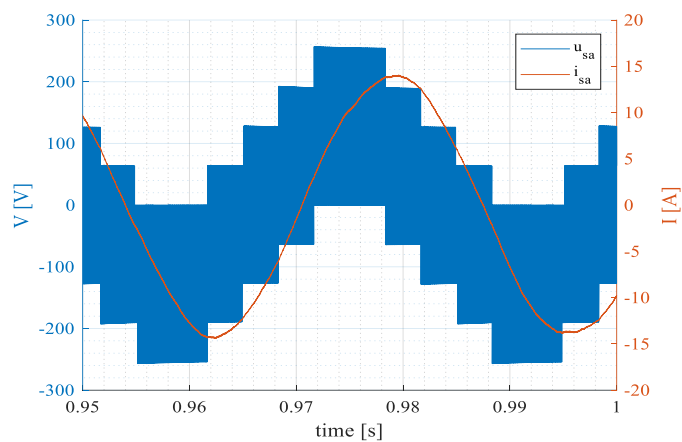

(b)

Fig. 8. Autonomous accu-battery mode through direct [0x5] MxC (a); autonomous accu-battery mode through direct [0x5] MxC (b).

In the case of $\mathrm{AB}+[0 \mathrm{x} 5] \mathrm{MxC}$ connection, the input voltage of [0x5] $\mathrm{MxC}$ equals to a voltage of $\mathrm{AB}$ battery $V_{D C}=V_{A B}$.

B. Comparing Power Losses (or Efficiency, Respectively) of Three- and Five- phase Indirect Controlled Matrix Converters of HEV Vehicle

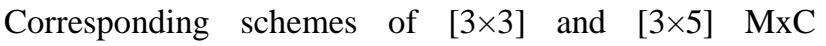
converters are presented in Fig. 9 and Fig. 10.

The direct control methods of $\mathrm{MxCs}$ are given in [8], [16].

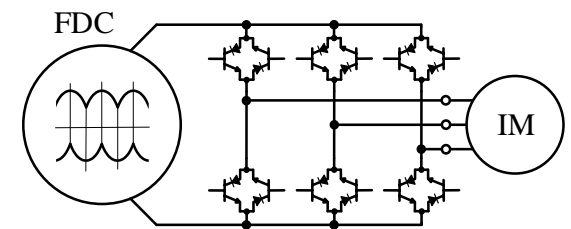

Fig. 9. Indirect controlled [3×3] MxC connections (FDC - fictitious DC link).

Similarly, in the case of $[3 \times 3] \mathrm{MxC}$ converter, it can be 
simulated phase voltages and currents and consequently power losses and efficiencies of power electronic switches.

To modeling of VSI inverters power losses, the Matlab/Simulink programming environment is used. The simulation scheme for power losses computation in Matlab/Simulink is given in Fig. 11.

In the case of indirect controlled [3×3] MxC connection, the power losses of used IGBTs and diodes (see Appendix A) reach the following values: carried-out simulation results are shown in Fig. 12, Fig. 13, and Fig. 14.

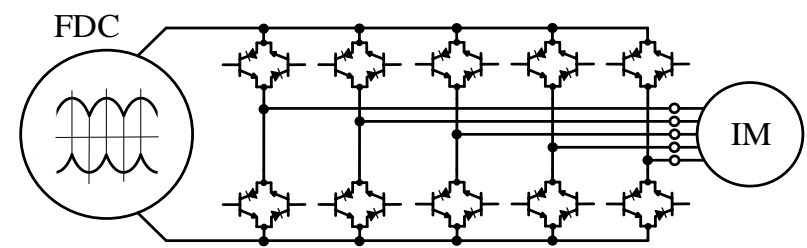

Fig. 10. Indirect controlled [3×5] MxC connections (FDC - fictitious DC link)

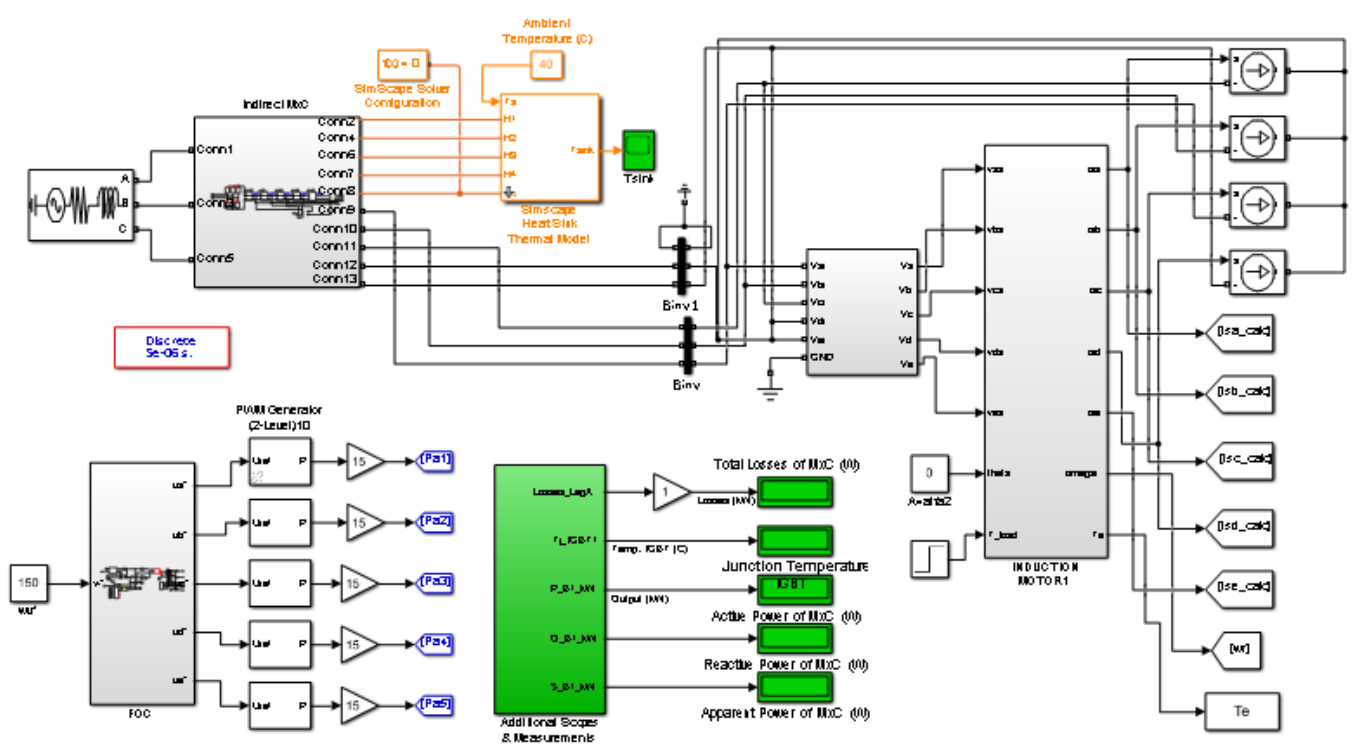

Fig. 11. Simulation scheme for power losses computation of indirect controlled MxC connection systems in Matlab/Simulink.

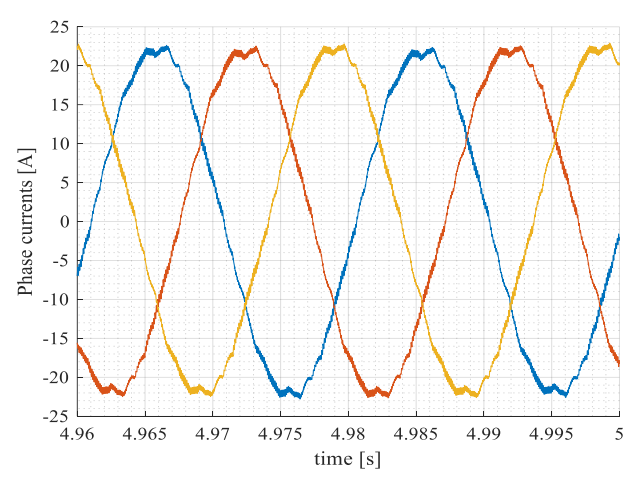

Fig. 12. Phase currents of $[3 \times 3]$ MxC connection.

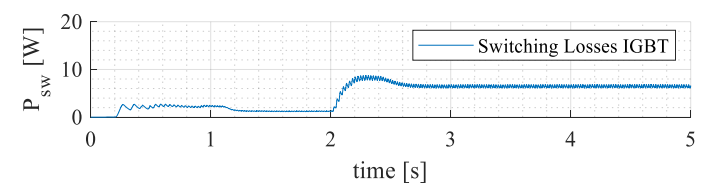

(a)

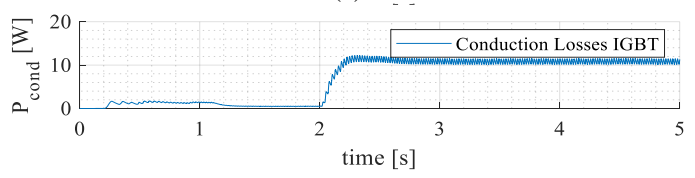

(b)

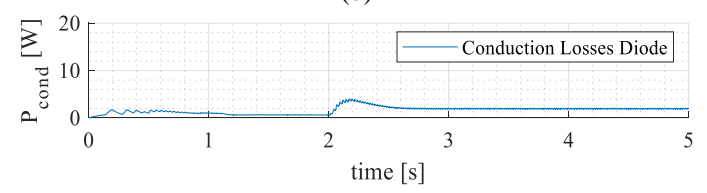

(c)

Fig. 13. Switching looses IGBT (a); Conduction looses IGBT (b) Conduction losses diode (c).

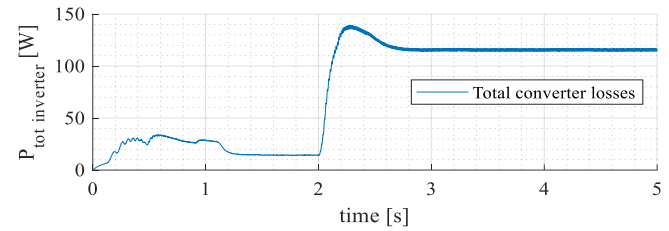

Fig. 14. Total losses of converter switches.

Calculated results from Matlab/Simulink simulation:

- Fundamental maximum phase voltage - $276 \mathrm{~V}$;

- Fundamental RMS value of phase voltage is

$V_{r m s}=276 / \sqrt{2}=196 \mathrm{~V}$;

- Maximum phase current - $22.5 \mathrm{~A}$;

- RMS value of phase current $-22.5 / \sqrt{2}=16 \mathrm{~A}$;

- Total [3×3] MxC switches power losses - $118 \mathrm{~W}$;

- The calculated total output power of [3×3] $\mathrm{MxC}$ converter is $S=3 \times 196 \times 16=9408$ VA.

- AVE value of output active power of [3×3] $\mathrm{MxC}$ converter is $P_{A V}=9408 \times 0.8(\cos \varphi)=7526 \mathrm{~W}$.

- Calculated energetic efficiency is $\eta=7526 /(7526+118) \times 100=98.45 \%$.

For thermal investigation, Foster thermal model is used, which is included in the datasheet of the transistors (Fig. 15).

The average junction temperature of IGBT is approximately $65^{\circ} \mathrm{C}$, which is allowed value.

Similarly, in the case of $[3 \times 5] \mathrm{MxC}$ converter, it can be simulated phase voltages and currents and consequently power losses, and efficiencies of power electronic switches. 


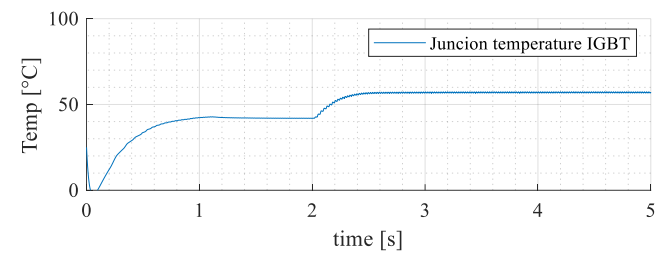

Fig. 15. Junction temperature of converter IGBT.

In the case of indirect controlled [3×5] $\mathrm{MxC}$ connection, the power losses of used IGBTs and diodes (Appendix B) reach the following values: carried-out simulation results are shown in Fig. 16, Fig. 17, and Fig. 18.

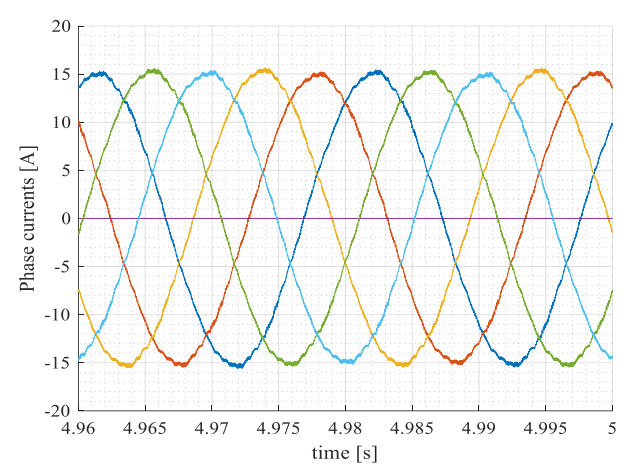

Fig. 16. Phase currents of $[3 \times 5] \mathrm{MxC}$ connection.

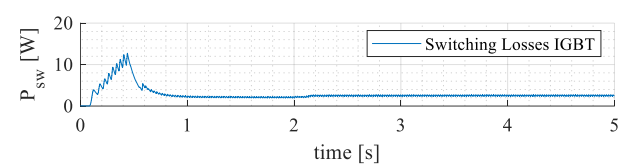

(a)

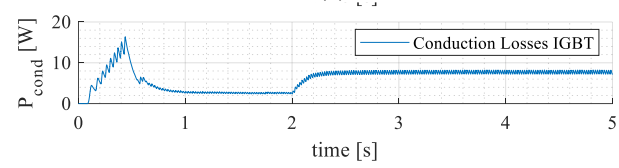

(b)

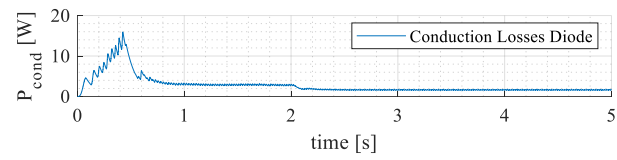

(c)

Fig. 17. Switching looses IGBT (a); Conduction looses IGBT (b); Conduction losses diode (c).

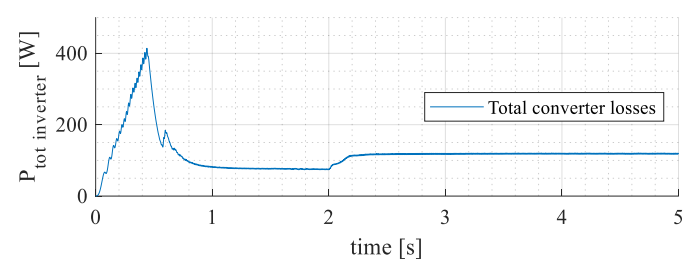

Fig. 18. Total losses of converter switches.

Calculated results from Matlab/Simulink simulation:

- Fundamental maximum phase voltage - 279 V;

- Fundamental RMS value of phase voltage

$V_{R M S}=276 / \sqrt{2}=198 \mathrm{~V}$ (overmodulation);

- Maximum phase current - $15 \mathrm{~A}$;

- RMS value of phase current $-15 / \sqrt{2}=10.6 \mathrm{~A}$;

- Total [3×5] MxC switches power losses - $122 \mathrm{~W}$;

- The calculated total output power of [3×5] $\mathrm{MxC}$ converter is $S=5 \times 198 \times 10.6=10613 \mathrm{VA}$;

- AVE value of output active power of [3×5] $\mathrm{MxC}$ converter is $P_{A V}=10613 \times 0.8(\cos \varphi)=8490 \mathrm{~W}$

- Calculated energetic efficiency is

$\eta=7526 /(7526+118) \times 100=98.45 \%$.

For thermal investigation, the Foster thermal model is used, which is included in the datasheet of the transistors (Fig. 19).

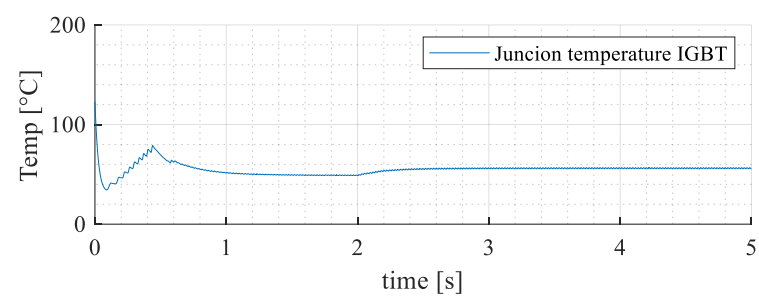

Fig. 19. The junction temperature of converter IGBT.

The average junction temperature of IGBT is approximately $65^{\circ} \mathrm{C}$, which is allowed value.

TABLE I. CALCULATED RESULTS FROM MATLAB/SIMULINK SIMULATIONS OF 3_PH/5_PH_CONVERTER

\begin{tabular}{|c|c|c|}
\hline Item & Name & $\begin{array}{c}\text { Value } \\
\mathbf{3 h} / \mathbf{5} \_\mathbf{p h}\end{array}$ \\
\hline$V_{R M S}$ & RMS value of phase voltage & $196 / 198 \mathrm{~V}$ \\
\hline$I_{R M S}$ & RMS value of phase current & $15.57 / 11.36 \mathrm{~A}$ \\
\hline$P_{A V E}$ & AVE value of output active power & $\begin{array}{c}7526 / 8 \\
490 \mathrm{~W}\end{array}$ \\
\hline$\Delta P_{V S I}$ & Total 5ph_VSI inverter power losses & $118 / 122 \mathrm{~W}$ \\
\hline$\eta_{V S I}$ & Energetic efficiency & $98.45 / 98.58 \%$ \\
\hline
\end{tabular}

\section{CONCLUSIONS}

Comparing calculated results given in Table I, we can conclude that the energetic efficiency of [3×3] $\mathrm{MxC}$ converter and $[3 \times 5] \mathrm{MxC}$ converter is nearly the same under the same output phase voltages and corresponding phase currents. Actually, the calculated efficiency of the 5ph_VSI inverter is slightly better (by $0.15 \%$ ). The average junction temperature of IGBT is approximately $65^{\circ} \mathrm{C}$ and it is equal in both cases. Under supposing of the same voltage and current circumstances, the similar efficiency is reached. The comparison of three-phase and five-phase VSI inverters supposed for HEV vehicles is presented in another paper (of this Conference, if accepted). To verify VSI inverters power losses and efficiencies the LT Spice circuit simulator, as well as a real test bed, in the next work are going to be used.

\section{APPENDIX A}

TABLE A-I. IGBT TRANSISTOR TYPE OF IKW25N120H3 PARAMETERS [17].

\begin{tabular}{|c|c|c|}
\hline VCES & $\begin{array}{c}\text { Collector-to-Emitter } \\
\text { Breakdown Voltage }\end{array}$ & $\mathbf{1 2 0 0} \mathbf{~ V}$ \\
\hline IC @ TC $=25^{\circ} \mathrm{C}$ & Continuous Collector Current & $50 \mathrm{~A}$ \\
\hline IC @ TC $=100^{\circ} \mathrm{C}$ & Continuous Collector Current & $25 \mathrm{~A}$ \\
\hline ICM & Pulsed Collector Current & $100 \mathrm{~A}$ \\
\hline $\mathrm{ILM}$ & $\begin{array}{c}\text { Clamped Inductive Load } \\
\text { Current }\end{array}$ & $100 \mathrm{~A}$ \\
\hline IF @ TC $=100^{\circ} \mathrm{C}$ & Diode Contin. Forward Current & $12.5 \mathrm{~A}$ \\
\hline $\mathrm{IFM}$ & Diode Max. Forward Current & $120 \mathrm{~A}$ \\
\hline
\end{tabular}




\begin{tabular}{|c|c|c|}
\hline VCES & $\begin{array}{c}\text { Collector-to-Emitter } \\
\text { Breakdown Voltage }\end{array}$ & $\mathbf{1 2 0 0} \mathbf{~ V}$ \\
\hline VGE & Gate-to-Emitter Voltage & $\pm 20 \mathrm{~V}$ \\
\hline PD @ TC $=25^{\circ} \mathrm{C}$ & Maximum Power Dissipation & $326 \mathrm{~W}$ \\
\hline PD @ TC $=100^{\circ} \mathrm{C}$ & Maximum Power Dissipation & $156 \mathrm{~W}$ \\
\hline $\mathrm{TJ}$ & $\begin{array}{c}\text { Operating Junction } \\
\text { Temperature }\end{array}$ & $-55+150^{\circ} \mathrm{C}$ \\
\hline
\end{tabular}

TABLE A-II. IGBT TRANSISTOR TYPE OF IKW15N120H3 PARAMETERS [17].

\begin{tabular}{|c|c|c|}
\hline VCES & $\begin{array}{l}\text { Collector-to-Emitter } \\
\text { Breakdown Voltage }\end{array}$ & $1200 \mathrm{~V}$ \\
\hline $\begin{array}{c}\mathrm{IC} @ \mathrm{TC}= \\
25^{\circ} \mathrm{C}\end{array}$ & Continuous Collector Current & $30 \mathrm{~A}$ \\
\hline $\begin{array}{c}\mathrm{IC} @ \mathrm{TC}= \\
100^{\circ} \mathrm{C}\end{array}$ & Continuous Collector Current & $15 \mathrm{~A}$ \\
\hline ICM & Pulsed Collector Current & $60 \mathrm{~A}$ \\
\hline ILM & $\begin{array}{c}\text { Clamped Inductive Load } \\
\text { Current }\end{array}$ & $60 \mathrm{~A}$ \\
\hline $\begin{array}{c}\text { IF @ } \mathrm{TC}= \\
100^{\circ} \mathrm{C}\end{array}$ & $\begin{array}{c}\text { Diode Continuous Forward } \\
\text { Current }\end{array}$ & $7.5 \mathrm{~A}$ \\
\hline IFM & $\begin{array}{c}\text { Diode Maximum Forward } \\
\text { Current }\end{array}$ & $60 \mathrm{~A}$ \\
\hline VGE & Gate-to-Emitter Voltage & $\pm 20 \mathrm{~V}$ \\
\hline $\begin{array}{c}\mathrm{PD} @ \mathrm{TC}= \\
25^{\circ} \mathrm{C}\end{array}$ & Maximum Power Dissipation & $217 \mathrm{~W}$ \\
\hline $\begin{array}{c}\mathrm{PD} @ \mathrm{TC}= \\
100^{\circ} \mathrm{C}\end{array}$ & Maximum Power Dissipation & $105 \mathrm{~W}$ \\
\hline $\mathrm{TJ}$ & $\begin{array}{l}\text { Operating Junction } \\
\text { Temperature }\end{array}$ & $-55^{\circ} \mathrm{C}$ to $+150^{\circ} \mathrm{C}$ \\
\hline
\end{tabular}

\section{REFERENCES}

[1] M. Ehsani, Y. Gao, and A. Emadi, Modern Electric, Hybrid-and Fuel Cell Vehicles. CRC Press, Boca Raton, USA, 2010, Chapter 4.

[2] B. Dobrucký, A.V. Karev, and I. Czeglédi, "Associated control system design of vehicle traction drive", in Proceedings of Electrical Drive \& Power Electronics Conference (EDPE'90), High Tatras, Slovakia, 1990, pp. 189-194.

[3] K. Hartani, M. Bourahla, Y. Miloud, M. Sekour, "Electronic Differential with Direct Torque Fuzzy Control for Vehicle Propulsion System", Turkish Journal of Electrical Engineering Computer Sciences, vol. 17, no. 1, pp. 21-38, 2009. DOI: 10.3906/elk-0801-1.

[4] T.J. Böhme and B. Frank, Hybrid Systems, Optimal Control and Hybrid Vehicles: Theory, Methods and Applications. Springer International Publishing AG, 2017, Part V. DOI: 10.1007/978-3-31951317-1.
[5] B Dobrucky, S. Kascak, and M. Prazenica, "A Novel enhanced connection of AC/AC powertrain for HEV - modelling and simulation results", Advances of Electrical and Electronic Engineering, vol. 16, no. 3, pp. 253-260, 2018. DOI: 10.15598/aeee.v16i3.2874.

[6] Improving of energetic efficiency of HEV vehicle by application of direct AC/AC powertrain, project proposal no. APVV-18-0291, Agency for research and development of Slovak Republic, Bratislava, 2018.

[7] S. Bernet, S. Ponnaluri, and R. Teichmann, "Design and loss comparison of matrix converters, and voltage-source converters for modern AC drives", IEEE Trans. on Industrial Electronics, vol. 49, no. 2, pp. 304-314, 2002. DOI: 10.1109/41.993263.

[8] P. Chlebiš, P. Šimoník, and M. Kabašta, "The comparison of direct and indirect matrix converters", in Proceedings of Progress in Electromagnetics Research Symposium (PIERS 2010), USA, 2010, pp. 310-313.

[9] B. Dobrucký, S. Kaščák, M. Praženica, and P. Pavlásek, "Direct ACAC propulsion system using matrix converter and 5-phase traction motor for HEV vehicle", Communications-Scientific Letters, vol. 20, no. 1, pp. 3-12, 2018.

[10] E. Levi, "Multiphase electric machines for variable-speed applications", IEEE Trans. On Ind. Electronics, vol. 55, no. 5, pp 18931909, 2008. DOI: 10.1109/TIE.2008.918488.

[11] M. M. Rezaoui, A. Kouzou, M. O. Mahmoudi, and L. Nezli, "Comparison performances between two matrix converters [3×3] and [3x5] supplying a multi-phases induction machine", Journal of Electrical Engineering, vol. 16, no. 1, pp. 217-227, 2016.

[12] S. M. Allam, Sherif M. Dabour, and Essam M. Rashad, "Three-tofive-phase matrix converter using carrier-based PWM technique", Journal of Renewable Energy and Sustainable Development (RESD), vol. 2, no. 2, pp. 96-111, 2016. DOI: 10.21622/RESD.2016.02.2.096

[13] M. Kabašta, "Modern Ways of Matrix Converter Control" (in Czech: Moderní spůsoby řízení maticových měničủ), Ph.D. Thesis, VSBTechnical University of Ostrava, Czech Republic, 2009.

[14] M. Takei, T. Naito, and K. Ueno, "The reverse blocking IGBT for matrix converter", in Proc. of PCIM Int'l Conference, Nurnberg (DE), pp. 1-6 (CD-ROM), 2003.

[15] P. Zaskalický, "Mathematical model of a five-phase voltage-source PWM controlled inverter", Electrical Engineering - Archiv für Elektrotechnik, Springer Verlag GmbH, Germany, vol. 99, no. 4, 2017. DOI: 10.1007/s00202-017-0643-y.

[16] B. Bednar, V. Blahnik, P. Drabek, and M. Pittermann, "Novel control strategy of single matrix traction converter - variable switching frequency", Electronics and Electrical Engineering, Kaunas (LT), Technologija, vol. 21, no. 5, pp. 13-18, 2015. DOI: 10.5755/j01.eee.21.5.13318.

[17] IGBT in Trench and Field-stop technology with soft, fast recovery anti-parallel diode - $1200 \mathrm{~V}$ highspeed switching series third generation. Infineon Technologies AG, Munich, Germany, 2014. 